\title{
Re-validation and adaptation of the Menstrual Practice Needs Scale to measure the menstrual experiences of adult women working in Mukono District, Uganda
}

\author{
Julie Hennegan (ORCID: 0000-0003-2011-1595) ${ }^{1,2}$ \\ Justine N. Bukenya (ORCID: 0000-0001-9139-6183) ${ }^{3}$ \\ Simon P.S. Kibira (ORCID: 0000-0002-7385-423X) ${ }^{3}$ \\ Petranilla Nakamya ${ }^{3}$ \\ Fredrick E. Makumbi (ORCID:0000-0002-6460-7325) ${ }^{4}$ \\ Natalie G. Exum ${ }^{2}$ \\ Kellogg J. Schwab (ORCID: 0000-0002-4966-8517)²

\footnotetext{
${ }^{1}$ Maternal, Child and Adolescent Health Program, Burnet Institute, Melbourne, VIC, Australia

${ }^{2}$ The Water Institute, Department of Environmental Health and Engineering, Johns Hopkins Bloomberg School of Public Health, Baltimore, MD, USA

${ }^{3}$ Department of Community Health and Behavioural Sciences, School of Public Health, College of Health Sciences, Makerere University, Kampala, Uganda

${ }^{4}$ Department of Epidemiology and Biostatistics, School of Public Health, College of Health Sciences, Makerere University, Kampala, Uganda
}

This is a preprint. Following peer-review of the manuscript, please see and cite the final version.

Correspondence:

Dr. Julie Hennegan

Burnet Institute

85 Commercial Rd Melbourne 3004, Victoria, Australia

julie.hennegan@burnet.edu.au

Twitter: julie hennegan 


\begin{abstract}
Objectives. The Menstrual Practice Needs Scale (MPNS) is a comprehensive measure of menstrual self-care experience including access to sufficient, comfortable absorbents, supportive spaces for managing menstruation and for disposal and laundering of used materials. It addresses a critical measurement gap to improve quantitative menstrual health research. The scale was validated in a population of adolescent schoolgirls. This study appraises its performance among adult women.
\end{abstract}

Methods. Seven cognitive interviews provided insights into the interpretability and acceptability of scale items. A cross sectional survey of 525 working women who had menstruated in the past six months (including 435 working in markets, 45 in schools and 45 working in health care facilities) in Mukono District, Uganda was used to test the dimensionality, reliability, and validity of the measure.

Results. The 36 scale items were well understood by the study population. Dimensionality was tested for the 28 items relevant to women disposing of menstrual materials and 32 items relevant to those washing and reusing materials. The original subscale structure fit with the data, however fell short of recommended thresholds for those disposing of materials (RMSEA $=0.069 ; \mathrm{CFI}=0.840$; $T L I=0.824$ ). An alternative sub-scale structure was an acceptable fit for those disposing (RMSEA = 0.051; $\mathrm{CFI}=0.911 ; \mathrm{TLI}=0.897$ ) and reusing materials (RMSEA $=0.053 ; \mathrm{CFI}=0.915 ; \mathrm{TLI}=0.904$ ). MPNS total and sub-scale scores demonstrated acceptable internal consistency. Higher scores reflected more positive menstrual experiences and were associated with greater wellbeing (total score $r=0.24$, $p<0.001$ ), not missing work due to the last menstrual period (total score $O R=2.4795 \% \mathrm{Cl} 1.42-4.30$ ), and confidence to manage menstruation at home and work.

Conclusions. The MPNS offers a valid and reliable way to assess menstrual health needs. The revised factor structure can be used for adult samples who work. Findings also highlight challenges in assessing the variety of experiences relevant to managing menstrual bleeding. 


\section{Introduction}

Efforts to improve menstrual health have rapidly grown around the globe. ${ }^{1-3}$ Governments, UN agencies, and civil society organisations have recognised the importance of menstruation in the lives of women, girls, and all people who menstruate, and the need to address menstrual health to achieve the Sustainable Development Goals..$^{4-6}$ To support these objectives, a growing body of evidence is emerging to understand menstrual health needs and investigate programme effectiveness. ${ }^{7-10}$ However, more research is needed and funding has been scarce. ${ }^{811} 12$ Quantitative studies have been limited by a lack of high quality measurement tools. ${ }^{613}{ }^{14}$ Systematic review and audit of the field found inconsistent and ad-hoc measures were often used, and concepts for measurement poorly defined. ${ }^{13}$ In response, recent efforts have sought to develop measures for core constructs, ${ }^{15-19}$ and identify indicators and measures for consistent use in research and monitoring. ${ }^{1420}$

The Menstrual Practice Needs Scale (MPNS) was developed to capture respondents' experiences of managing their menstrual bleeding. ${ }^{15}$ The measure was informed by a systematic review and synthesis of qualitative research across low- and middle-income countries (LMICs) which found women's and girls' perceptions of their menstrual management practices and environments to be a crucial component of their menstrual experience. ${ }^{7}$ Items in the MPNS were drawn from participant narratives reported across studies in the review. This included participants' perceptions about their access to and quality of menstrual materials, the availability and security of disposal and storage options, comfort transporting and storing materials, and perceived accessibility, cleanliness, privacy, and safety of menstrual management environments. The MPNS is aligned with the requirements for achieving menstrual health outlined in the recently published menstrual health definition, including that: all people who experience a menstrual cycle are able to "care for their bodies during menstruation such that their preferences, hygiene, comfort, privacy, and safety are supported." 3 The MPNS provides a self-reported, quantitative measure of this requirement.

The MPNS was validated in a population of adolescent schoolgirls in Soroti, Uganda and administered in Ateso, a regional Ugandan language. ${ }^{15} \mathrm{~A}$ final 36 -item measure with six subscales was developed. Sub-scales had adequate reliability, and validity was established through hypothesised associations with girls' reported confidence to measure menstruation, self-reported school absenteeism and wellbeing, and known groups comparing disposable pad users and nonusers..$^{15}$ To the best of our knowledge, the performance of the measure has not been tested in other languages or population groups such as adult women.

Menstrual health research and practice in LMICs has focused on adolescent girls as a priority population for safeguarding menstrual health and supporting education at this critical developmental stage. ${ }^{21} 22$ However, menstrual needs continue into adulthood and there is increasing recognition of their importance. ${ }^{32-25}$ Studies highlighting unmet menstrual needs among adult women are emerging, finding that women report consequences for their health, wellbeing, participation at work, and uptake and continued use of contraceptive methods. ${ }^{26-29}$ While the items included in the MPNS were designed to be applicable to adult women, the performance of the measure in this population is untested.

\section{The present study}

In this study we used cognitive interviews and a cross-sectional survey among women working in Mukono District, Uganda to test the acceptability, dimensionality, validity, and reliability of the MPNS among an adult sample. Findings will inform the use of the measure in this population. 


\section{Methods}

This study uses data collected as part of a larger exploratory sequential mixed-methods study aiming to understand the sanitation and menstrual experiences of adult women working in Mukono District, Uganda. ${ }^{26}$ The STROBE Checklist ${ }^{30}$ is included as Supplementary Materials 1.

\section{Study sample}

The population were adult women aged 18-45 working in markets, government primary schools and public health care facilities (HCFs) in the Mukono district. In collaboration with the local government, we identified all markets in the district operating for at least 8 hours per day and 3 days per week $(n=10)$. In markets, women were systematically sampled proportional to the estimated population of female workers based on site observations and advice from market leaders. Enumerators mapped and sampled $50 \%$ of the population in each market, and $20 \%$ in the largest market in the municipality to ensure sufficient experiences from smaller markets were captured. Women were eligible for participation if they worked at least 3 days per week over the last month, ineligible women were replaced by the next eligible worker. We sampled teachers and HCF workers at the sites in closest geographic proximity to the markets, surveying 5 for each market to reach a total of 50 teachers and $50 \mathrm{HCF}$ workers. Where there were less than 5 eligible participants at the closest school or HCF we continued to the next until the sample size was reached. Teachers and HCF workers were sampled based on their availability.

The sample size was designed for power and precision to estimate the prevalence and impacts of unmet sanitation and menstrual needs on health and work participation. For the purposes of revalidating the MPNS, our sample exceeded the recommended 10 participants per survey item, requiring 360 participants for the 36 -item scale. ${ }^{31}$

\section{Cognitive Interviews}

Seven, hour-long cognitive interviews were undertaken to test the interpretability of the survey, including the MPNS items. Participants were purposively sampled and included six women from markets spread from ages 20-43 and one teacher. Interviews were undertaken in February 2020. Participants were asked to 'think aloud' or explain their answer, to anticipate the type of responses other women may provide, or to reframe the question in their own words.

Interviews were conducted by JB and PN, with JH supporting 2 interviews. Interviewers made written notes on printed copies of the survey, including notable quotations.

\section{Data collection}

Surveys were conducted in March 2020 by a team of 10 female enumerators. Enumerators were university graduates and had prior experience administering surveys on sexual and reproductive health and water, sanitation and hygiene (WASH) topics and received 5 days of training. Questions were delivered verbally in Luganda or English, and answers entered into the survey using Open Data Kit (ODK) loaded on smartphones. Participants provided written consent for survey or cognitive interview. Interviews and surveys were undertaken with auditory, and if possible, visual privacy. Surveys lasted 45-60 minutes, and participants received a bar of soap in appreciation for their participation. 


\section{Measures}

Survey measures were developed in English and translated to Luganda by bilingual researchers (JNB, SPSK, PN) along with back-translation. The full survey is available on the project page: www.osf.io/nzitq.

Menstrual Practice Needs Scale (MPNS). ${ }^{15}$ All MPNS items ask respondents about experiences during their last menstrual period. The interview version of the scale was used, and questions are displayed in results tables. Participants responded on a 4-point scale: Never, Less than half the time, More than half the time, Always. This alternative to the original 'Never, Sometimes, Often, Always' response options was drawn from the WHO- 5 scale $^{32} 33$ with the aim of achieving more balanced distribution across middle responses. Positively worded items were scored from 0 (never) to 3 (always), and negatively worded items from 3 (never) to 0 (always). Total and sub-scale scores were calculated as a mean score for all relevant items with higher scores representing more positive experiences. Where respondents indicated questions were not applicable (e.g., those who did not dispose of any materials or did not attend work during menstruation) the total score reflects the mean of relevant questions, sub-scales are not calculated where more than 1 item was not applicable to the respondent.

Demographics and menstrual practices. Demographic questions captured participant age, role at their workplace, level of education, and marital status. Poverty was assessed using five items from the Afrobarometer lived poverty index ${ }^{34}$ scored on a 5-point response scale asking how often over the past 12 months participants' household went without food, water, medicines, fuel for cooking or a cash income. A total score across the five index items was calculated with a lowest possible score of 0 and maximum 20, with higher scores representing greater poverty.

Menstrual practices were captured using items from the Menstrual Practices Questionnaire. ${ }^{35} \mathrm{We}$ describe the practice profile of the sample using the core items suggested for report in menstrual health research including the type of material used, frequency of change, and change and disposal locations. ${ }^{35}$

Mental health. Psychological wellbeing was assessed using the World Health Organisation Wellbeing Index (WHO-5). ${ }^{32}$ The measure has been used across contexts with high validity. Responses were indicated across the 6-point response scale with raw scores from 0 to 25 multiplied by 4 to give a total score from 0 to 100, with higher scores indicating greater wellbeing.

Confidence to manage menstruation. Participants were asked "How confident do you feel that you can manage your menstruation [pad yourself, change your materials, dispose of them or wash and dry them] when you are at home/during your work day?" with four response options form "very unconfident" to "very confident". Dichotomous variables were used for analysis with 'very confident' and 'not very confident' used for home confidence, and 'confident' and 'not confident' for work.

Work absenteeism. Participants were asked "Did you miss work due to your last menstrual period?", with Yes/No responses used dichotomously to capture absenteeism due to menstruation.

\section{Analysis}

Analyses were undertaken using Stata 15 and R v4.1.0. Descriptive statistics highlight item responses. Confirmatory Factor Analysis (CFA) using the lavaan package ${ }^{36}$ in $\mathrm{R}$ was undertaken using a robust diagonally weighted least squares estimator (DWLS). DWLS requires complete data. Participants who had not disposed of any menstrual materials did not have responses for items 11 to 14. Factor structure was thus investigated separately for those who reused materials, and for those 
who disposed of materials. Forty-four women did not attend any days of work during their last menstrual period or did not change their menstrual materials during the workday. As these participants had missing responses to MPNS items 24-28 they were excluded from CFAs. Consistent with current guidance, we considered a root mean squared error of approximation (RMSEA) $\leq 0.05$ as indicative of a close fit and RMSEA $\leq 0.08$ as indicative of a fair fit. ${ }^{38}$ We considered Comparative Fit Index (CFI) and Trucker-Lewis Index (TLI) $\geq 0.95$ as indicative of a close fit and $\geq 0.90$ as an acceptable fit. ${ }^{37}$ Robust estimates are presented. Finding near acceptable but not close fit for the previously validated factor structure, we investigated an alternative structure. This included inspection of the polychoric correlation matrix and exploratory factor analysis (EFA) with oblique rotation (promax), along with investigating model fit through examination of factor loadings, residual correlations, and modification indices.

We present internal consistency for the original and revised scales calculated using polychoric correlations to provide an ordinal alpha ( $\alpha_{\text {ordinal }}$ ) as appropriate for the four-item response scale, ${ }^{39}$ using 0.70 as indicative of satisfactory reliability. We also provide Cronbach's alpha for comparison.

Validity was tested through hypothesised relationships with lived poverty, wellbeing, confidence to manage menstruation at home and work, and self-reported work absenteeism tested using Person's correlation coefficients and binary logistic regressions. We also compared scores between worker groups and commercial pad and non-pad users.

\section{Results}

\section{Cognitive Interviews}

Seven women participated in cognitive interviews, two had some primary school education, three had secondary education, and two had tertiary education. All participants reported that questions capturing menstrual experiences were acceptable when asked by a female interviewer. MPNS items were well comprehended, including the four-point response scale. Asking participants to "think aloud" when answering questions or explain their answer showed a clear understanding of the scale items, and the variety of circumstances that impact on women's experiences and thus their responses. Selected verbatim explanations of item responses are displayed in Table 1.

One item (MPN 10) was amended based on cognitive interview feedback from "Did you feel comfortable storing your menstrual materials until your next period?" to "Did you feel comfortable storing [keeping] your leftover or cleaned menstrual materials until your next period?" for clarity. 
Table 1. Selected quotations from cognitive interview participants explaining their response selection.

\begin{tabular}{|c|c|}
\hline $\begin{array}{l}\text { MPN1 } \\
\text { During your last menstrual period, were your } \\
\text { menstrual materials comfortable? }\end{array}$ & $\begin{array}{l}\text { More than half of the time. } \\
\text { "I didn't have enough so had to stay longer [before } \\
\text { changing] and it became uncomfortable." }\end{array}$ \\
\hline $\begin{array}{l}\text { MPN2 } \\
\text { During your last menstrual period, did you have } \\
\text { enough of your menstrual materials to change } \\
\text { them as often as you wanted to? }\end{array}$ & $\begin{array}{l}\text { More than half of the time. } \\
\text { "When I have to, I hold back a bit, because I think it's } \\
\text { expensive" }\end{array}$ \\
\hline $\begin{array}{l}\text { MPN4 } \\
\text { During your last menstrual period, could you get } \\
\text { more of your menstrual materials when you } \\
\text { needed to? }\end{array}$ & $\begin{array}{l}\text { Participant noted that less than 'always' response } \\
\text { would be if she "can't get home or to the store to } \\
\text { buy" }\end{array}$ \\
\hline $\begin{array}{l}\text { MPN5 } \\
\text { Were you worried that your menstrual materials } \\
\text { would allow blood to pass through to your outer } \\
\text { garments? }\end{array}$ & $\begin{array}{l}\text { Always. } \\
\text { "I have a heavy flow, so I am always worried that my } \\
\text { pad might overflow" }\end{array}$ \\
\hline $\begin{array}{l}\text { MPN9 } \\
\text { Did you feel comfortable carrying menstrual } \\
\text { materials to the place where you changed them? }\end{array}$ & $\begin{array}{l}\text { Less than half the time } \\
\text { "Fear that other women or people in the market will } \\
\text { know that I am in periods" }\end{array}$ \\
\hline $\begin{array}{l}\text { MPN20 } \\
\text { When at home during your last period, were you } \\
\text { worried that someone would see you while you } \\
\text { were changing your menstrual materials? }\end{array}$ & $\begin{array}{l}\text { Never. } \\
\text { "I always change before my husband comes home, I } \\
\text { am never worried because I know his schedule" }\end{array}$ \\
\hline $\begin{array}{l}\text { MPN20 } \\
\text { When at home during your last period, were you } \\
\text { worried that someone would see you while you } \\
\text { were changing your menstrual materials? }\end{array}$ & $\begin{array}{l}\text { Never. } \\
\text { "I'm not bothered. I have my own room and I'm not } \\
\text { worried about my husband seeing me" } \\
\text { However, this participant noted that when washing } \\
\text { her materials, she is worried about privacy. The } \\
\text { bathroom is near the bedroom and then she worries } \\
\text { that her husband will see her. }\end{array}$ \\
\hline $\begin{array}{l}\text { MPN35 } \\
\text { During your last menstrual period, were you } \\
\text { worried that your menstrual materials would not } \\
\text { be dry when you needed them? }\end{array}$ & $\begin{array}{l}\text { "You may wash them and hang them whenever you } \\
\text { want, but they will not necessarily be dry when you } \\
\text { want" } \\
\text { "So yes, I was always worried they would not be dry } \\
\text { when I needed them" [despite reporting she could } \\
\text { 'always' dry her materials when she wanted to]. }\end{array}$ \\
\hline $\begin{array}{l}\text { MPN36 } \\
\text { During your last menstrual period, were you } \\
\text { worried that others would see your menstrual } \\
\text { materials while they were drying? }\end{array}$ & $\begin{array}{l}\text { "Yes, always. Even sometimes you dry and then you } \\
\text { cover" [due to being worried that other people would } \\
\text { see drying materials]. }\end{array}$ \\
\hline
\end{tabular}

Two further insights were fed back through enumerators administering the survey. First, that some women expressed the sentiment that no one had ever asked them about their satisfaction or worries around their menstrual management practices before and thus needed time to consider their answers. This was consistent with the findings from the qualitative portion of the study ${ }^{26}$ in which cleanliness and secrecy in menstrual management were prioritized, regardless of discomforts endured. Second, some women felt there were too many scale items, with duplicated items asking about experiences at home and at work taking too long to complete. 


\section{Survey Participants}

A total 600 adult women participated in the Women and Workplaces survey, this included 500 women working in markets, 50 teachers, and 50 health care facility staff members. Of these participants, $87.5 \%$ had menstruated in the past 6 months and were eligible to answer questions about their menstrual experience. For this study, a total 525 participants, including 435 working in markets, 45 in health care facilities, and 45 working in schools were included.

Sample ages ranged from 18 to 45 years with a mean of 30.6 . A total $35.8 \%$ of the sample had attended primary or no school, $46.5 \%$ had attended secondary school, and $17.7 \%$ had postsecondary training. Most of the sample (80.7\%) identified as Christian, with the remaining $19.2 \%$ identifying as Muslim. A total $60.8 \%$ were currently married or cohabitating.

The median number of working days was 6 , with $28.6 \%$ of women working 6 days and $41.5 \%$ working 7 days a week. On days worked, participants reported spending a median 12 hours at the workplace.

As menstrual material, women reported most often using pads ( $70.6 \%$ at work, $68.6 \%$ at home), followed by cloth ( $16.5 \%$ at work, $18.3 \%$ at home), and reusable pads ( $8.2 \%$ at work, $7.6 \%$ at home) with the final $4.7 \%$ at work and $5.52 \%$ at home using other materials such as toilet paper, cotton wool or underwear alone during their last period. At home, most women disposed of used materials into latrines (80.5\%) and approximately a third (27.6\%) washed and reused materials during their last period. Most women reported changing menstrual materials three times in 24 hours on the heaviest day of their period $(49.8 \%)$, with others changing twice $(28.8 \%)$ or four times (13.9\%). When at home during their last period, most women changed their menstrual materials in their bedroom (42.2\%), followed by the latrine $(20.5 \%)$. While at work, most participants $(61.4 \%)$ changed in the sanitation facility most often, while others reported most often going home to change $(26.4 \%)$ or used a bathroom or other location at work (12.2\%).

\section{Item responses}

Table 2 displays participant responses to each MPNS item. Item means, standard deviation, skew and kurtosis are included in Supplementary Materials 2. Many women reported positive menstrual management experiences, particularly at home. Environments at work were rated more poorly, and many women reported insecurities around their menstrual practices at least some of the time. Approximately $20 \%$ of respondents did not dispose of any menstrual materials during their last period, consistent with the proportion using reusables. An error in ODK coding meant that 42 women were not asked item 28 and have missing data. Approximately $8 \%$ of respondents reported that they did not ever change their menstrual materials during the workday or did not attend any work during their last period, resulting in a reduced sample of women responding to items 23-28.

Table 2. Participant responses to MPNS-36 items $(n=525)$

\begin{tabular}{|c|c|c|c|c|c|c|}
\hline No. Item & $\begin{array}{l}\text { Never } \\
\%\end{array}$ & $\begin{array}{c}\text { Less } \\
\text { than half } \\
\%\end{array}$ & $\begin{array}{c}\text { More } \\
\text { than half } \\
\%\end{array}$ & $\begin{array}{c}\text { Always } \\
\%\end{array}$ & $\begin{array}{l}\text { NA } \\
\%(n)\end{array}$ & $\begin{array}{l}\text { Missing } \\
\%(n)\end{array}$ \\
\hline 1. Were your menstrual materials comfortable? & 3.24 & 11.81 & 14.86 & 70.1 & & \\
\hline $\begin{array}{l}\text { 2. Did you have enough of your menstrual materials to } \\
\text { change them as often as you wanted to? }\end{array}$ & 1.71 & 8.76 & 13.52 & 76.00 & & \\
\hline $\begin{array}{l}\text { 3. Were you satisfied with the cleanliness of your } \\
\text { menstrual materials? }\end{array}$ & 1.53 & 4.58 & 11.83 & 82.06 & & $0.19(1)$ \\
\hline
\end{tabular}




\begin{tabular}{|c|c|c|c|c|c|c|}
\hline $\begin{array}{l}\text { 4. Could you get more of your menstrual materials when } \\
\text { you needed to? }\end{array}$ & 2.29 & 11.62 & 13.52 & 72.57 & & \\
\hline $\begin{array}{l}\text { 5. Were you worried that your menstrual materials would } \\
\text { allow blood to pass through to your outer garments? }\end{array}$ & 36.19 & 26.86 & 18.1 & 18.86 & & \\
\hline $\begin{array}{l}\text { 6. Were you worried that your menstrual materials would } \\
\text { move from place while you were wearing them? }\end{array}$ & 50.67 & 22.18 & 9.75 & 17.40 & & $0.38(2)$ \\
\hline $\begin{array}{l}\text { 7. Were you worried about how you would get more of } \\
\text { your menstrual material if you ran out? }\end{array}$ & 60.76 & 18.86 & 12.76 & 7.62 & & \\
\hline $\begin{array}{l}\text { 8. Did you feel comfortable carrying spare menstrual } \\
\text { materials with you outside your home? }\end{array}$ & 18.15 & 12.36 & 14.48 & 55.02 & & $1.33(7)$ \\
\hline $\begin{array}{l}\text { 9. Did you feel comfortable carrying menstrual materials } \\
\text { to the place where you changed them? }\end{array}$ & 12.57 & 14.12 & 14.51 & 58.8 & & $1.52(8)$ \\
\hline $\begin{array}{l}\text { 10. Did you feel comfortable storing [keeping] your } \\
\text { leftover or cleaned menstrual materials until your next } \\
\text { period? }\end{array}$ & 6.29 & 4.38 & 5.9 & 83.43 & & \\
\hline $\begin{array}{l}\text { 11. Were you able to wash your hands when you wanted } \\
\text { to? }\end{array}$ & 2.48 & 6.1 & 8.38 & 83.05 & & \\
\hline $\begin{array}{l}\text { 12. Were you able to immediately dispose of your used } \\
\text { menstrual materials? }\end{array}$ & 4.08 & 6.24 & 10.55 & 79.14 & $\begin{array}{l}20.19 \\
(106)\end{array}$ & $0.38(2)$ \\
\hline $\begin{array}{l}\text { 13. Were you able to dispose of your used materials in the } \\
\text { way that you wanted to? }\end{array}$ & 5.29 & 6.73 & 10.82 & 77.16 & $\begin{array}{l}20.76 \\
(109)\end{array}$ & \\
\hline $\begin{array}{l}\text { 14. Were you worried about where to dispose of your } \\
\text { used menstrual materials? }\end{array}$ & 70.38 & 10.9 & 6.4 & 12.32 & $\begin{array}{l}19.62 \\
(103)\end{array}$ & \\
\hline $\begin{array}{l}\text { 15. Were you concerned that others would see your used } \\
\text { menstrual materials in the place you disposed of them? }\end{array}$ & 65.18 & 12.72 & 7.81 & 14.29 & $\begin{array}{c}14.48 \\
(76)\end{array}$ & $0.19(1)$ \\
\hline $\begin{array}{l}\text { 16. When at home, were you able to change your } \\
\text { menstrual materials when you wanted to? }\end{array}$ & 0.57 & 1.9 & 5.71 & 91.81 & & \\
\hline $\begin{array}{l}\text { 17. When at home, were you satisfied with the place you } \\
\text { used to change your menstrual materials? }\end{array}$ & 0.57 & 2.86 & 9.52 & 87.05 & & \\
\hline $\begin{array}{l}\text { 18. When at home, did you have a clean place to change } \\
\text { your menstrual materials? }\end{array}$ & 0.57 & 2.1 & 7.82 & 89.5 & & $0.19(1)$ \\
\hline
\end{tabular}

19. When at home, were you worried that you would not be able to change your menstrual materials when you needed to?

$\begin{array}{llll}85.71 & 7.05 & 2.86 & 4.38\end{array}$

20. When at home, were you worried that someone would see you while you were changing your menstrual materials?

$\begin{array}{llll}78.86 & 10.48 & 4.95 & 5.71\end{array}$

21. When at home, were you worried that someone would harm you while I you were changing your menstrual materials?

92.38

4.38

1.52

22. When at home, were you worried that something else would harm you while you were changing your menstrual materials (e.g., animals, unsafe structure) $\begin{array}{llll}90.48 & 7.05 & 1.14 & 1.33\end{array}$ 23. When at work, were you able to change your menstrual materials when you wanted to?

3.52

24. When at work, were you satisfied with the place you

used to change your menstrual materials?

25 . When at work, did you have a clean place to change your menstrual materials?

14.85

16.15

13.66

66.67

$8.00(42)$

26. When at work, were you worried that you would not be able to change your menstrual materials when you needed to?

27. When at work, sere you worried that someone would see you while you were changing your menstrual materials? 


\begin{tabular}{|c|c|c|c|c|c|c|}
\hline $\begin{array}{l}\text { 28. When at work, were you worried that someone would } \\
\text { harm you while you were changing your menstrual } \\
\text { materials? }\end{array}$ & 80.94 & 8.74 & 4.71 & 5.61 & $7.05(37)$ & $\begin{array}{l}8.00 \\
(42)^{*}\end{array}$ \\
\hline \multicolumn{7}{|l|}{ Among those reusing menstrual materials ( $n=145$ ) } \\
\hline $\begin{array}{l}\text { 29. Did you have enough water to soak or wash your } \\
\text { menstrual materials? }\end{array}$ & 0.69 & 3.45 & 18.62 & 77.24 & & \\
\hline $\begin{array}{l}\text { 30. Did you have access to a basin or bucket to soak or } \\
\text { wash your menstrual materials whenever you needed it? }\end{array}$ & 0.00 & 2.07 & 12.41 & 85.52 & & \\
\hline $\begin{array}{l}\text { 31. Were you able to wash your menstrual materials } \\
\text { whenever you wanted to? }\end{array}$ & 4.14 & 11.72 & 17.24 & 66.9 & & \\
\hline $\begin{array}{l}\text { 32. Did you have enough soap to wash your menstrual } \\
\text { materials? }\end{array}$ & 0.69 & 8.97 & 17.93 & 72.41 & & \\
\hline $\begin{array}{l}\text { 33. Were you able to dry your materials when you wanted } \\
\text { to? }\end{array}$ & 6.9 & 11.72 & 24.14 & 57.24 & & \\
\hline $\begin{array}{l}\text { 34. Were you worried that someone would see you while } \\
\text { I you were washing your menstrual materials? }\end{array}$ & 53.1 & 17.24 & 13.1 & 16.55 & & \\
\hline $\begin{array}{l}\text { 35. Were you worried that your menstrual materials } \\
\text { would not be dry when you needed them? }\end{array}$ & 52.41 & 22.07 & 20.69 & 4.83 & & \\
\hline $\begin{array}{l}\text { 36. Were you worried that others would see your } \\
\text { menstrual materials while they were drying? }\end{array}$ & 48.97 & 17.24 & 14.48 & 19.31 & & \\
\hline
\end{tabular}

NA: Not Applicable, *these participants were missing due to a skip pattern error during data collection.

\section{Dimensionality}

Table 3 displays the factor loadings and robust model fit statistics for the original MPNS structure. The original four-factor structure for those disposing of menstrual materials during the last period showed a fair fit for the data based on absolute fit test (RMSEA $=0.069,90 \% \mathrm{Cl} 0.064-0.075$ ) but unacceptable fit based on tests comparing to a null model ( $C F I=0.840, T L I=0.824)$. Sensitivity analyses excluding item 28 where cases had missing data due to a skip error allowed us to test the structure in the larger sample of 371 but did not change the findings (RMSEA $=0.073,90 \% \mathrm{Cl} 0.068$ 0.078; $\mathrm{CFI}=0.844 ; \mathrm{TLI}=0.828$ ). The full six-factor structure was a fair fit for the data based on absolute and comparative fit statistics for those who reused materials (RMSEA $=0.052,90 \% \mathrm{Cl} 0.040-0.063$; $\mathrm{CFI}=0.922 ; \mathrm{TLI}=0.913)$, and the two-factor solution for the reuse items alone showed good fit (RMSEA $=0.05090 \% \mathrm{Cl} 0.00-0.094 ; \mathrm{CFI}=0.984 ; \mathrm{TLI}=0.977$ ).

Table 3. Confirmatory Factor Analysis (CFA) standardised factor loadings and model fit statistics for the original four and two factor structure

\begin{tabular}{|c|c|c|c|}
\hline No. Item & $\begin{array}{l}\text { CFA for those } \\
\text { disposing of } \\
\text { materials }\end{array}$ & $\begin{array}{l}\text { CFA for those } \\
\text { reusing } \\
\text { materials }\end{array}$ & $\begin{array}{l}\text { CFA for only } \\
\text { reuse items }\end{array}$ \\
\hline $\mathbf{N}$ & $\mathrm{N}=335$ & $\mathrm{~N}=125$ & $\mathrm{~N}=145$ \\
\hline \multicolumn{4}{|l|}{ Material and home environment needs } \\
\hline 1. Were your menstrual materials comfortable? & 0.415 & 0.580 & \\
\hline $\begin{array}{l}\text { 2. Did you have enough of your menstrual materials to change } \\
\text { them as often as you wanted to? }\end{array}$ & 0.704 & 0.693 & \\
\hline $\begin{array}{l}\text { 3. Were you satisfied with the cleanliness of your menstrual } \\
\text { materials? }\end{array}$ & 0.551 & 0.675 & \\
\hline $\begin{array}{l}\text { 4. Could you get more of your menstrual materials when you } \\
\text { needed to? }\end{array}$ & 0.707 & 0.851 & \\
\hline $\begin{array}{l}\text { 10. Did you feel comfortable storing [keeping] your leftover or } \\
\text { cleaned menstrual materials until your next period? }\end{array}$ & 0.501 & 0.759 & \\
\hline 11. Were you able to wash your hands when you wanted to? & 0.603 & 0.614 & \\
\hline
\end{tabular}




\begin{tabular}{|c|c|c|c|}
\hline $\begin{array}{l}\text { 12. Were you able to immediately dispose of your used } \\
\text { menstrual materials? }\end{array}$ & 0.522 & - & \\
\hline $\begin{array}{l}\text { 13. Were you able to dispose of your used materials in the way } \\
\text { that you wanted to? }\end{array}$ & 0.590 & - & \\
\hline $\begin{array}{l}\text { 16. When at home, were you able to change your menstrual } \\
\text { materials when you wanted to? }\end{array}$ & 0.494 & 0.652 & \\
\hline $\begin{array}{l}\text { 17. When at home, were you satisfied with the place you used } \\
\text { to change your menstrual materials? }\end{array}$ & 0.596 & 0.666 & \\
\hline $\begin{array}{l}\text { 18. When at home, did you have a clean place to change your } \\
\text { menstrual materials? }\end{array}$ & 0.644 & 0.704 & \\
\hline Material reliability & & & \\
\hline $\begin{array}{l}\text { 5. Were you worried that your menstrual materials would } \\
\text { allow blood to pass through to your outer garments? }\end{array}$ & 0.619 & 0.867 & \\
\hline $\begin{array}{l}\text { 6. Were you worried that your menstrual materials would } \\
\text { move from place while you were wearing them? }\end{array}$ & 0.636 & 0.689 & \\
\hline $\begin{array}{l}\text { 7. Were you worried about how you would get more of your } \\
\text { menstrual material if you ran out? }\end{array}$ & 0.776 & 0.638 & \\
\hline Transport and work & & & \\
\hline $\begin{array}{l}\text { 8. Did you feel comfortable carrying spare menstrual materials } \\
\text { with you outside your home? }\end{array}$ & 0.418 & 0.544 & \\
\hline $\begin{array}{l}\text { 9. Did you feel comfortable carrying menstrual materials to the } \\
\text { place where you changed them? }\end{array}$ & 0.676 & 0.598 & \\
\hline $\begin{array}{l}\text { 23. When at work, were you able to change your menstrual } \\
\text { materials when you wanted to? }\end{array}$ & 0.718 & 0.596 & \\
\hline $\begin{array}{l}\text { 24. When at work, were you satisfied with the place you used } \\
\text { to change your menstrual materials? }\end{array}$ & 0.876 & 0.894 & \\
\hline $\begin{array}{l}\text { 25. When at work, did you have a clean place to change your } \\
\text { menstrual materials? }\end{array}$ & 0.931 & 1.00 & \\
\hline Insecurity & & & \\
\hline $\begin{array}{l}\text { 14. Were you worried about where to dispose of your used } \\
\text { menstrual materials? }\end{array}$ & 0.612 & - & \\
\hline $\begin{array}{l}\text { 15. Were you concerned that others would see your used } \\
\text { menstrual materials in the place you disposed of them? }\end{array}$ & 0.642 & - & \\
\hline $\begin{array}{l}\text { 19. When at home, were you worried that you would not be } \\
\text { able to change your menstrual materials when you needed to? }\end{array}$ & 0.289 & 0.332 & \\
\hline $\begin{array}{l}\text { 20. When at home, were you worried that someone would see } \\
\text { you while you were changing your menstrual materials? }\end{array}$ & 0.513 & 0.703 & \\
\hline $\begin{array}{l}\text { 21. When at home, were you worried that someone would } \\
\text { harm you while I you were changing your menstrual materials? }\end{array}$ & 0.485 & 0.615 & \\
\hline $\begin{array}{l}\text { 22. When at home, were you worried that something else } \\
\text { would harm you while you were changing your menstrual } \\
\text { materials (e.g., animals, unsafe structure) }\end{array}$ & 0.608 & 0.759 & \\
\hline $\begin{array}{l}\text { 26. When at work, were you worried that you would not be } \\
\text { able to change your menstrual materials when you needed to? }\end{array}$ & 0.776 & 0.629 & \\
\hline $\begin{array}{l}\text { 27. When at work, were you worried that someone would see } \\
\text { you while you were changing your menstrual materials? }\end{array}$ & 0.778 & 0.797 & \\
\hline $\begin{array}{l}\text { 28. When at work, were you worried that someone would } \\
\text { harm you while you were changing your menstrual materials? }\end{array}$ & 0.712 & 0.736 & \\
\hline Among those reusing menstrual materials $(n=145)$ & & & \\
\hline Reuse needs & & & \\
\hline $\begin{array}{l}\text { 29. Did you have enough water to soak or wash your menstrual } \\
\text { materials? }\end{array}$ & & 0.783 & 0.729 \\
\hline $\begin{array}{l}\text { 30. Did you have access to a basin or bucket to soak or wash } \\
\text { your menstrual materials whenever you needed it? }\end{array}$ & & 0.700 & 0.746 \\
\hline
\end{tabular}




\begin{tabular}{|c|c|c|c|}
\hline $\begin{array}{l}\text { 31. Were you able to wash your menstrual materials whenever } \\
\text { you wanted to? }\end{array}$ & & 0.739 & 0.796 \\
\hline $\begin{array}{l}\text { 32. Did you have enough soap to wash your menstrual } \\
\text { materials? }\end{array}$ & & 0.689 & 0.587 \\
\hline 33. Were you able to dry your materials when you wanted to? & & 0.614 & 0.619 \\
\hline \multicolumn{4}{|l|}{ Reuse insecurity } \\
\hline $\begin{array}{l}\text { 34. Were you worried that someone would see you while I you } \\
\text { were washing your menstrual materials? }\end{array}$ & & 0.862 & 0.888 \\
\hline $\begin{array}{l}\text { 35. Were you worried that your menstrual materials would not } \\
\text { be dry when you needed them? }\end{array}$ & & 0.592 & 0.588 \\
\hline $\begin{array}{l}\text { 36. Were you worried that others would see your menstrual } \\
\text { materials while they were drying? }\end{array}$ & & 0.730 & 0.734 \\
\hline RMSEA $(90 \% \mathrm{Cl})$ & $\begin{array}{c}0.069 \\
(0.064-0.075) \\
\end{array}$ & $\begin{array}{c}0.052 \\
(0.040-0.063) \\
\end{array}$ & $\begin{array}{c}0.050 \\
(0.00-0.094) \\
\end{array}$ \\
\hline CFI & 0.840 & 0.922 & 0.984 \\
\hline TLI & 0.824 & 0.913 & 0.977 \\
\hline
\end{tabular}

Based on the fit statistics and visual inspection of the polychoric correlation matrix we explored an alternative factor structure. We observed correlations between all disposal-related items (items 12, 13,14 , and 15) and noted the challenges in assessing fit for those who did not dispose of any materials. Scree plot, eigenvalue, and factor loadings on an EFA undertaken on these items alone suggested a one-factor solution to be a good fit. In testing the internal consistency of this scale, we found that reliability was improved with the removal of item 12 .

In testing the adequacy of the remaining items for EFA, very high correlations between items capturing satisfaction with, and cleanliness of, the sanitation facilities at home (items 17 and 18 correlated 0.80 ) and at work (items 24 and 25 correlated 0.89 ) were identified. We also found that high endorsement of item 21, with most women 'never' worried they would be harmed when changing their menstrual materials at home resulted in a not positive definite matrix. We removed items 18 and 25, retaining only 17 and 24, and removed item 21. The Kaiser-Meyer-Olkin sampling adequacy was then adequate $(\mathrm{KMO}=0.66)$. EFA suggested a three-factor solution, grouping items related to experiences in the workplace, material and home needs, and material and home environment insecurities. Item 11 (handwashing) loaded across multiple new sub-scales (home, home insecurity, and workplace needs) and was removed. Item 8 was weakly loaded on the workplace factor (0.35) and was removed.

While the proportion of women who feared someone would harm them while changing their menstrual materials at home was low (item 21), for those who did report fear this is a priority concern and content validity would be reduced by removing this item. One negative polychoric correlation was observed, between item 21 (fearing for safety at home) and item 16 (being able to change whenever the respondent wanted to) (polychoric correlation $=-0.30$ ). Item 16 was removed in favour of item 21 to resolve the issue. To preserve balance across the number of items relating to different parts of menstrual experience, we removed item 7 , which also cross-loaded on insecurity and home needs scales, along with item 30 as the reuse item with the weakest loading.

The revised factor structure, loadings and model fit statistics are displayed in Table 4 . We found the revised subscales were a good fit for the data among those disposing of materials and those reusing materials. We also noted that our comparative fit indices were constrained by a high performing nul model (with a RMSEA $=0.160$ ), with a null RMSEA of 0.158 rendering comparative fit statistics unable to exceed $0.90 .^{40} \mathrm{Visual}$ inspection of the polychoric correlation matrix suggests the well performing 
null model this was driven by low correlations between items regarding home changing facilities and those capturing concerns at work, as well as worries about the performance of menstrual materials and items capturing satisfaction with the environment at home. This was consistent with the subscale structure and our understanding of menstrual experiences.

The revised scale includes a total 28 items: 21 items for those who did not reuse any materials, and 25 items for those who reused but did not dispose of any items.

Subscales were all positively correlated (correlations displayed in Supplementary Materials 2).

Scores on the revised total scale ranged from 1.1 to 3.0, with the distribution of revised total scores presented in Figure 1. A total 2.1\% of total scores were between 0.50 and $1.49,41.3 \%$ of scores between 1.50 and 2.49 , and $56.6 \%$ of participants scored between 2.5 and 3.0 .

Table 4. Confirmatory Factor Analysis (CFA) standardised factor loadings and model fit statistics for the revised factor structure

\begin{tabular}{|c|c|c|c|}
\hline No. Item & $\begin{array}{l}\text { CFA for those } \\
\text { disposing of } \\
\text { materials }\end{array}$ & $\begin{array}{l}\text { CFA for those } \\
\text { reusing } \\
\text { materials }\end{array}$ & $\begin{array}{l}\text { CFA for only } \\
\text { reuse items }\end{array}$ \\
\hline $\mathbf{N}$ & $\mathrm{N}=335$ & $\mathrm{~N}=125$ & $\mathrm{~N}=145$ \\
\hline \multicolumn{4}{|l|}{ Material and home environment needs } \\
\hline 1. Were your menstrual materials comfortable? & 0.515 & 0.613 & \\
\hline $\begin{array}{l}\text { 2. Did you have enough of your menstrual materials to change } \\
\text { them as often as you wanted to? }\end{array}$ & 0.747 & 0.702 & \\
\hline $\begin{array}{l}\text { 3. Were you satisfied with the cleanliness of your menstrual } \\
\text { materials? }\end{array}$ & 0.606 & 0.671 & \\
\hline $\begin{array}{l}\text { 4. Could you get more of your menstrual materials when you } \\
\text { needed to? }\end{array}$ & 0.736 & 0.875 & \\
\hline $\begin{array}{l}\text { 10. Did you feel comfortable storing [keeping] your leftover or } \\
\text { cleaned menstrual materials until your next period? }\end{array}$ & 0.463 & 0.740 & \\
\hline $\begin{array}{l}\text { 17. When at home, were you satisfied with the place you used } \\
\text { to change your menstrual materials? }\end{array}$ & 0.339 & 0.382 & \\
\hline \multicolumn{4}{|l|}{ Material and home environment insecurity } \\
\hline $\begin{array}{l}\text { 5. Were you worried that your menstrual materials would } \\
\text { allow blood to pass through to your outer garments? }\end{array}$ & 0.634 & 0.803 & \\
\hline $\begin{array}{l}\text { 6. Were you worried that your menstrual materials would } \\
\text { move from place while you were wearing them? }\end{array}$ & 0.669 & 0.654 & \\
\hline $\begin{array}{l}\text { 19. When at home, were you worried that you would not be } \\
\text { able to change your menstrual materials when you needed to? }\end{array}$ & 0.370 & 0.365 & \\
\hline $\begin{array}{l}20 . \text { When at home, were you worried that someone would see } \\
\text { you while you were changing your menstrual materials? }\end{array}$ & 0.625 & 0.733 & \\
\hline $\begin{array}{l}\text { 21. When at home, were you worried that someone would } \\
\text { harm you while I you were changing your menstrual materials? }\end{array}$ & 0.578 & 0.685 & \\
\hline $\begin{array}{l}\text { 22. When at home, were you worried that something else } \\
\text { would harm you while you were changing your menstrual } \\
\text { materials (e.g., animals, unsafe structure) }\end{array}$ & 0.708 & 0.788 & \\
\hline \multicolumn{4}{|l|}{ Disposal needs } \\
\hline $\begin{array}{l}\text { 13. Were you able to dispose of your used materials in the way } \\
\text { that you wanted to? }\end{array}$ & 0.618 & & \\
\hline $\begin{array}{l}\text { 14. Were you worried about where to dispose of your used } \\
\text { menstrual materials? }\end{array}$ & 0.758 & & \\
\hline
\end{tabular}


15. Were you concerned that others would see your used menstrual materials in the place you disposed of them?

0.783

\begin{tabular}{|c|c|c|c|}
\hline Work practice needs & & & \\
\hline $\begin{array}{l}\text { 9. Did you feel comfortable carrying menstrual materials to the } \\
\text { place where you changed them? }\end{array}$ & 0.584 & 0.642 & \\
\hline $\begin{array}{l}\text { 23. When at work, were you able to change your menstrual } \\
\text { materials when you wanted to? }\end{array}$ & 0.692 & 0.555 & \\
\hline $\begin{array}{l}\text { 24. When at work, were you satisfied with the place you used } \\
\text { to change your menstrual materials? }\end{array}$ & 0.718 & 0.653 & \\
\hline $\begin{array}{l}\text { 26. When at work, were you worried that you would not be } \\
\text { able to change your menstrual materials when you needed to? }\end{array}$ & 0.757 & 0.65 & \\
\hline $\begin{array}{l}\text { 27. When at work, sere you worried that someone would see } \\
\text { you while you were changing your menstrual materials? }\end{array}$ & 0.777 & 0.841 & \\
\hline $\begin{array}{l}\text { 28. When at work, were you worried that someone would } \\
\text { harm you while you were changing your menstrual materials? }\end{array}$ & 0.712 & 0.783 & \\
\hline Among those reusing menstrual materials $(n=145)$ & & & \\
\hline Reuse needs & & & \\
\hline $\begin{array}{l}\text { 29. Did you have enough water to soak or wash your menstrual } \\
\text { materials? }\end{array}$ & & 0.715 & 0.649 \\
\hline $\begin{array}{l}\text { 31. Were you able to wash your menstrual materials whenever } \\
\text { you wanted to? }\end{array}$ & & 0.761 & 0.856 \\
\hline $\begin{array}{l}\text { 32. Did you have enough soap to wash your menstrual } \\
\text { materials? }\end{array}$ & & 0.691 & 0.615 \\
\hline 33. Were you able to dry your materials when you wanted to? & & 0.599 & 0.603 \\
\hline Reuse insecurity & & & \\
\hline $\begin{array}{l}\text { 34. Were you worried that someone would see you while I you } \\
\text { were washing your menstrual materials? }\end{array}$ & & 0.859 & 0.902 \\
\hline $\begin{array}{l}\text { 35. Were you worried that your menstrual materials would not } \\
\text { be dry when you needed them? }\end{array}$ & & 0.605 & 0.584 \\
\hline $\begin{array}{l}\text { 36. Were you worried that others would see your menstrual } \\
\text { materials while they were drying? }\end{array}$ & & 0.723 & 0.724 \\
\hline RMSEA $(90 \% \mathrm{Cl})$ & $\begin{array}{c}0.051 \\
(0.043-0.060)\end{array}$ & $\begin{array}{c}0.053 \\
(0.038-0.067)\end{array}$ & $\begin{array}{c}0.036 \\
(0.00-0.094)\end{array}$ \\
\hline CFI & 0.911 & 0.915 & 0.993 \\
\hline TLI & 0.897 & 0.904 & 0.989 \\
\hline
\end{tabular}


Figure 1. Distribution of revised MPNS total scores in the study sample

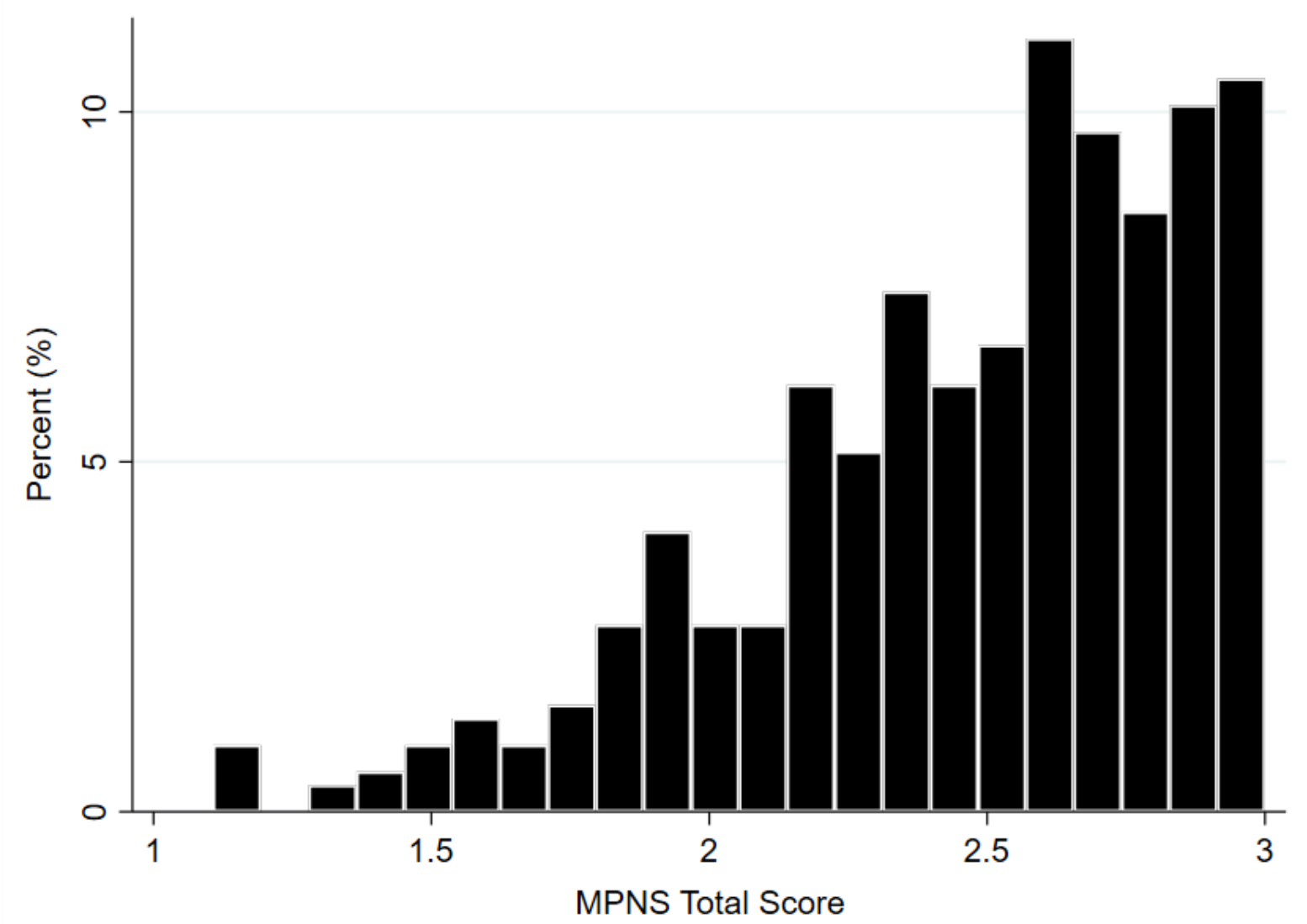

\section{Reliability}

Table 5 displays the mean, standard deviation and internal consistency of the total and subscale scores for both the original and revised scales. Both versions exhibited acceptable reliability assessed with an ordinal alpha. Home and environment needs scales, which were similar across the original and revised sub-scale structures, suffered slightly poorer reliability in the revised version due to a smaller number of items.

\section{Validity}

Mean scores were high across the sub-scales and total score. Women reported greater unmet needs in relation to their work environment, and laundering experiences. This was consistent with reports during the cognitive interviews. Table 5 displays the bivariate relationships between sub and total scale scores and hypothesised correlates. Greater poverty was associated with decreased MPNS score. Significant relationships between MPNS scores and mental health assessed through the WHO5 were observed across original and revised scale structures. Total scores showed a moderate $(0.25)$ association with mental health, while among the subscales material and home needs showed the strongest association. Having higher levels of menstrual needs met was associated with increased odds that women did not miss work due to their last period. In both the original and revised structure, work-related needs were not significantly associated with absenteeism, which may indicate a stronger role of material needs. These relationships also suffer from missing cases where 
those absent from the workplace were unable to report on their experiences at work. Having more met needs at work did translate into significantly higher odds of feeling confident to manage menstruation in the workplace and was not associated with confidence managing menstruation at home, supporting the validity of these subscales. Tests of scale validity were broadly comparable between the original and revised approaches.

As hypothesised, and consistent with the original validation, participants using commercially produced disposable or reusable pads $(M=2.49)$ had higher MPNS scores (revised measure) than those using improvised materials $(M=2.38),(t(512)=2.45, p=0.007)$. 
Table 5. Original and revised scale reliability and validity

\begin{tabular}{|c|c|c|c|c|c|c|c|c|c|}
\hline & Mean & $S D$ & $\alpha_{\text {ordinal }}$ & $\alpha$ & $\begin{array}{l}\text { Lived poverty } \\
\text { index } \\
r \text { (p-value) }\end{array}$ & $\begin{array}{l}\text { WHO-5 } \\
\text { r (p-value) }\end{array}$ & $\begin{array}{l}\text { Did not miss } \\
\text { work due to last } \\
\text { period } \\
\text { OR }(95 \% \mathrm{Cl})\end{array}$ & $\begin{array}{l}\text { Very confident } \\
\text { managing } \\
\text { menses at home } \\
\text { OR }(95 \% \mathrm{Cl})\end{array}$ & $\begin{array}{l}\text { Confident } \\
\text { managing } \\
\text { menses at work } \\
\text { OR }(95 \% \mathrm{Cl}) \\
\end{array}$ \\
\hline \multicolumn{10}{|l|}{ Original Subscales } \\
\hline $\begin{array}{l}\text { Material and home environment needs } \\
(n=525)\end{array}$ & 2.70 & 0.33 & 0.81 & 0.65 & $-0.25(<.001)$ & $0.24(<.001)$ & $1.86(0.95-3.64)$ & $4.11(2.19-7.73)$ & $3.88(2.21-6.83)$ \\
\hline Insecurity ( $n=525)$ & 2.06 & 0.82 & 0.83 & 0.71 & $-0.34(<.001)$ & $0.15(<.001)$ & $1.80(1.14-2.83)$ & $1.13(0.79-1.62)$ & $4.49(2.99-6.76)$ \\
\hline Material reliability concerns $(n=523)$ & 2.54 & 0.49 & 0.71 & 0.64 & $-0.32(<.001)$ & $0.19(<.001)$ & $1.57(1.18-2.08)$ & $1.13(0.92-1.41)$ & $2.27(1.80-2.87)$ \\
\hline Transport and work needs $(n=483)$ & 2.16 & 0.78 & 0.83 & 0.76 & $-0.26(<.001)$ & $0.15(<.001)$ & $1.15(0.84-1.59)$ & $0.97(0.76-1.22)$ & 2.60 (1.99-3.39) \\
\hline Reuse needs $(n=145)$ & 2.59 & 0.47 & 0.83 & 0.66 & $-0.30(<.001)$ & $0.18(.032)$ & $1.62(0.73-3.60)$ & $1.74(0.79-3.81)$ & $2.19(1.04-4.61)$ \\
\hline Reuse insecurity $(n=145)$ & 2.08 & 0.86 & 0.77 & 0.69 & $-025(<.001)$ & $0.25(.003)$ & $1.75(1.11-2.76)$ & $2.39(1.49-3.84)$ & $1.29(0.88-1.89)$ \\
\hline Total score (original) $(n=525)$ & 2.48 & 0.38 & 0.93 & 0.87 & $-0.39(<.001)$ & $0.25(<.001)$ & $2.58(1.43-4.63)$ & $1.76(1.09-2.84)$ & $\begin{array}{l}12.10(6.78- \\
21.56)\end{array}$ \\
\hline \multicolumn{10}{|l|}{ Revised Adult Subscales } \\
\hline $\begin{array}{l}\text { Material and home environment needs } \\
(\mathrm{n}=525)\end{array}$ & 2.66 & 0.40 & 0.72 & 0.57 & $-0.34(<.001)$ & $0.26(<.001)$ & $1.83(1.08-3.13)$ & $3.73(2.18-6.36)$ & $2.32(1.48-3.63)$ \\
\hline Material and home insecurity $(n=525)$ & 2.50 & 0.47 & 0.74 & 0.56 & $-0.25(<.001)$ & $0.17(<.001)$ & $2.31(1.45-3.67)$ & $1.31(0.90-1.92)$ & $3.32(2.20-5.01)$ \\
\hline Disposal $(n=421)$ & 2.42 & 0.77 & 0.77 & 0.64 & $-0.09(.078)$ & $0.06(.216)$ & $1.16(0.82-1.64)$ & $1.01(0.78-1.30)$ & $2.13(1.62-2.81)$ \\
\hline Work practice needs $(n=481)$ & 2.26 & 0.73 & 0.86 & 0.79 & $-0.36(<.001)$ & $0.14(.002)$ & $1.30(0.93-1.81)$ & $0.89(0.70-1.15)$ & $3.51(2.59-4.75)$ \\
\hline Reuse needs $(n=145)$ & 2.53 & 0.53 & 0.79 & 0.64 & $-0.31(<.001)$ & $0.18(.029)$ & $1.55(0.77-3.10)$ & $1.48(0.76-2.91)$ & $1.91(1.00-3.65)$ \\
\hline Reuse insecurity $(n=145)$ & 2.08 & 0.86 & 0.77 & 0.69 & $-0.24(<.001)$ & $0.25(.003)$ & $1.75(1.11-2.76)$ & $2.39(1.49-3.84)$ & $1.29(0.88-1.89)$ \\
\hline Total score (revised) $(n=525)$ & 2.47 & 0.40 & 0.91 & 0.85 & $-0.39(<.001)$ & $0.24(<.001)$ & $2.47(1.42-4.30)$ & $1.64(1.05-2.57)$ & $\begin{array}{l}10.19(5.94- \\
17.51)\end{array}$ \\
\hline
\end{tabular}




\section{Discussion}

This study tested and adapted the Menstrual Practice Needs Scale (MPNS) for use in a population of adult working women in Mukono District, Uganda. Through cognitive interviews and enumerator training we found the measure was acceptable and comprehensible to the study population. The four-point response scale was well understood, and previously suggested modifications of midpoints to "less than half the time" and "more than half the time" resulted in more balanced use of these options. Cognitive interviews and survey responses were consistent with the in-depth qualitative findings capturing women's experiences of menstruating at work. ${ }^{26}$ Women reported more positive perceptions of menstrual management locations at home than in the workplace. Approximately 70$80 \%$ of women were satisfied with the comfort, quantity, and cleanliness of their materials, consistent with interview reports that women highly valued and prioritised purchase of preferred menstrual materials. At the same time, many reported worrying about soiling or accessing materials, also consistent with qualitative interviews where many participants reported these anxieties. ${ }^{26}$

Women in this study reported more positive experiences of managing menstruation (mean score 2.47) than adolescent girls in the original validation in Soroti (mean score 1.82). ${ }^{15}$ While it remains unclear if scores are directly comparable across study populations, this finding is consistent with the hypothesis that urban working women are likely to have greater access to resources and more experience managing menstruation than adolescents. Further, in the original validation, schools for the study were selected by the local government as those in greatest need of support in Soroti, an area with greater poverty than Mukono. ${ }^{154142}$

In testing the dimensionality of the scale among adults, the original factor structure identified for adolescents was not the best fit for the data. Although near acceptable fit was noted on some metrics, an alternative structure represented a better fit. This was driven by a greater consistency between women's insecurities and their comfort and satisfaction with their practices. The original validation study found null or negative associations between satisfaction and insecurities, with negative correlations identified between these factors. ${ }^{15}$ In the present study, these items remained on separate factors for material and home environment needs but grouped together in capturing women's practice needs in relation to disposal and experiences at work. The finding suggests that adult women, who have more years' experience of menstruation than adolescents, have more realistically calibrated their concerns with their satisfaction. It may also suggest that women's experiences at work are less informed by their experiences at home, in contrast to adolescents where worries about access, privacy and safety at home and school covaried more closely. ${ }^{15}$

Our findings suggest that a shorter, revised subscale structure can be used for adult women. In our study sample, we found that questions capturing satisfaction with the location used to change menstrual materials were near synonymous with items asking if the location was clean, suggesting that women's satisfaction was most influenced by cleanliness. This is consistent with the qualitative findings from the research program, where women expressed concern and disgust in response to unclean facilities and worries about contracting infections. ${ }^{26}$ However, it is unclear if this relationship would be observed for other samples and further testing would support dropping or retaining these items in other populations.

In developing a revised subscale structure, we found that some items with applicability across home and work locations (e.g., availability of handwashing) were cross loaded. This indicates that respondents are correctly taking both home and work experiences into account in their response. While this accurately represents menstrual experiences, it presents challenges for developing 
parsimonious subscales. Future research using the MPNS in service of different research questions can provide guidance on the use of generalized items in contrast to location specific items.

Construct validity was demonstrated through relationships between the MPNS and hypothesised correlates, and differences between known groups. Significant correlations between the MPNS and poverty index were consistent with the role of resource deficits in menstrual experience. ${ }^{710}$ MPNS scores were also associated with absence from work in bivariate analyses. Having a higher level of met menstrual practice needs was associated with feeling confident to manage menstruation at home and at work, with subscale relationships further supporting validity.

\section{Strengths and limitations}

Cognitive interviews and enumerator training helped to refine items and confirmed the interpretability of questions. However, the applicability of items for those reusing or disposing of materials split the sample for which we could test dimensionality. Removing items that do not apply to all respondents would simplify analysis but would greatly dimmish the content validity of the measure. Similarly, those who do not change their menstrual materials during the workday or avoid work entirely during menstruation are unable to report on their experiences of changing or managing menstrual needs at work. This also presents a challenge for the assessment of the subscale structure and relationships with work absenteeism when those missing work also do not have responses on these items. However, again, removal of these items would reduce content validity and fail to capture important experiences for those who do manage their bleeding in the workplace. $^{25} 26$

Further research is needed to investigate the cross-cultural validity of the measure, particularly dimensionality, in other populations. While this study tested the performance in a large sample, the sample was not large enough to explore differences across worker groups, with a small proportion of teachers and health care workers included, or in different adult age groups or life stages which may show further variation. ${ }^{4344}$

\section{Implications for research and practice}

The Menstrual Practice Needs Scale offers a reliable and valid way to measure menstrual management experiences. This study re-validated the measure in an adult working population and offers a revised subscale structure for this group. The adult version of the measure can be used to consistently assess the menstrual experiences of women in research and for practice monitoring and evaluation. This work equips quantitative studies to build the evidence to understand the contributors to and consequences of unmet menstrual health needs and to evaluate the performance of interventions; a critical evidence gap for improving menstrual health. 


\section{Ethical approvals}

Ethical approval was provided by Makerere University School of Public Health Higher Degrees, Research and Ethics Committee (HDREC: 739) and Johns Hopkins Bloomberg School of Public Health Institutional Review Board (IRB: 00010015). The Uganda National Council for Science and Technology (UNCST) approved the study (ref: SS 5143).

Workplace administrators (Headteachers, Health Care Facility Administrators and Market Chairpersons) permitted recruitment of participants from their workplaces. Approval for the study in the area was also provided by the Mukono district chief administrator's office and the Mukono Municipality Town clerk's office.

\section{Patient and Public Involvement}

The MPNS was developed with input from NGO practitioners as potential users of the measure. Patients and Public were not involved in this revalidation study.

\section{Acknowledgements}

We are grateful to the participating workplaces and women who shared their experiences. We thank our skilled enumerator team.

\section{Funding}

This study was supported by the Osprey Foundation of Maryland. JH time was supported by The Case for Her. The funders had no role in study design, data collection, analysis, decision to publish, or preparation of the manuscript.

\section{Contributions}

Julie Hennegan: Conceptualization; Methodology; Formal analysis; Investigation; Data Curation; Writing - Original draft; Visualization; Supervision; Project administration. Justine N. Bukenya: Methodology; Investigation; Validation; Writing - Reviewing \& Editing; Supervision. Simon PS Kibira: Methodology; Investigation; Writing - Reviewing \& Editing; Supervision; Project administration. Petranilla Nakamya: Investigation; Data Curation; Project administration; Writing - Reviewing \& Editing. Natalie G. Exum: Methodology; Validation; Writing - Reviewing \& Editing. Fredrick E. Makumbi: Methodology; Validation; Writing - Review \& Editing; Supervision. Kellogg J. Schwab: Conceptualization; Validation; Resources; Writing - Review \& Editing; Supervision; Project administration; Funding acquisition.

All authors have approved the final manuscript.

\section{Data sharing statement}

Deidentified data relevant to the analysis presented in this publication are available on the study Open Science Framework page: www.osf.io/nzjtq

\section{Competing interests}

All authors declare no competing interests. 


\section{References}

1. Sommer M, Sahin M. Overcoming the Taboo: Advancing the Global Agenda for Menstrual Hygiene Management for Schoolgirls. American journal of public health 2013;103(9):1556-59.

2. Bobel C. Making Menstruation Matter in the Global South: Mapping a Critical History. The Managed Body: Springer 2019:69-109.

3. Hennegan J, Winkler IT, Bobel C, et al. Menstrual Health: A Definition for Policy, Practice, and Research. Sexual and Reproductive Health Matters 2021;29(1):1-8. doi: doi.org/10.1080/26410397.2021.1911618

4. Sommer M, Torondel B, Hennegan J, et al. How addressing menstrual health and hygiene may enable progress across the Sustainable Development Goals. Global Health Action 2021;14(1):1920315.

5. Tellier S, Hyttel M. Menstrual Health Management in East and Southern Africa: a Review Paper. South Africa: UNFPA, 2018.

6. Plesons M, Patkar A, Babb J, et al. The state of adolescent menstrual health in low-and middleincome countries and suggestions for future action and research. Reproductive Health 2021;18(1):1-13.

7. Hennegan J, Shannon AK, Rubli J, et al. Women's and girls' experiences of menstruation in lowand middle-income countries: a systematic review and qualitative metasynthesis. PLOS Medicine 2019;16(5):e1002803. doi: https://doi.org/10.1371/journal.pmed.1002803

8. Amaya L, Marcatili, J., Bhavaraju, N. Advancing Gender Equity by Improving Menstrual Health. Online: FSG, 2020.

9. Barrington DJ, Robinson $\mathrm{HJ}$, Wilson $\mathrm{E}$, et al. Experiences of menstruation in high income countries: A systematic review, qualitative evidence synthesis and comparison to low- and middleincome countries. PloS ONE 2021;16(7):e0255001. doi: https://doi.org/10.1371/journal.pone.0255001

10. Crichton J, Okal J, Kabiru CW, et al. Emotional and Psychosocial Aspects of Menstrual Poverty in Resource-Poor Settings: A Qualitative Study of the Experiences of Adolescent Girls in an Informal Settlement in Nairobi. Health Care for Women International 2013;34(10):891-916. doi: 10.1080/07399332.2012.740112

11. Phillips-Howard PA, Caruso B, Torondel B, et al. Menstrual hygiene management among adolescent schoolgirls in low-and middle-income countries: research priorities. Global health action 2016;9(1):33032.

12. Kulczyk Foundation, Founders Pledge. A Bloody Problem: Period Poverty, why we need to end it and how to do it. Poland: Kulczyk Foundation, 2020.

13. Hennegan J, Brooks DJ, Schwab KJ, et al. Measurement in the study of menstrual health and hygiene: A systematic review and audit. Plos One 2020;15(6):e0232935. doi: https://doi.org/10.1371/journal.pone.0232935

14. UNICEF. Guidance for Monitoring Menstrual Health and Hygiene. New York: UNICEF, 2020.

15. Hennegan J, Nansubuga A, Smith C, et al. Measuring menstrual hygiene experience: development and validation of the Menstrual Practice Needs Scale (MPNS-36) in Soroti, Uganda. BMJ open 2020;10(2)

16. HAVER J, LONG JL, CARUSO BA, et al. New Directions for Assessing Menstrual Hygiene Management (MHM) in Schools: A Bottom-Up Approach to Measuring Program Success. Studies in Social Justice 2018;12(2):372-81.

17. Caruso BA, Portela G, McManus S, et al. Assessing Women's Menstruation Concerns and Experiences in Rural India: Development and Validation of a Menstrual Insecurity Measure. International journal of environmental research and public health 2020;17(10):3468.

18. Garg S, Marimuthu Y, Bhatnagar N, et al. Development and validation of a menstruation-related activity restriction questionnaire among adolescent girls in urban resettlement colonies of 
Delhi. Indian Journal of Community Medicine: Official Publication of Indian Association of Preventive \& Social Medicine 2021;46(1):57.

19. Hunter E. Self-efficacy in addressing menstrual needs: Construct conceptualization and measurement in Bangladeshi schoolgirls. Johns Hopkins University, 2019.

20. Sommer M, Zulaika G, Schmitt M, et al. Monitoring Menstrual Health and Hygiene: Measuring Progress for Girls on Menstruation; Meeting Report. New York \& Geneva: Columbia University and WSSCC, 2019.

21. Ibitoye $M$, Choi $C$, Tai $H$, et al. Early menarche: A systematic review of its effect on sexual and reproductive health in low-and middle-income countries. PloS one 2017;12(6):e0178884.

22. Sommer M, Sutherland C, Chandra-Mouli V. Putting menarche and girls into the global population health agenda. Reproductive health 2015;12(1):24.

23. Baker KK, Padhi B, Torondel B, et al. From menarche to menopause: A population-based assessment of water, sanitation, and hygiene risk factors for reproductive tract infection symptoms over life stages in rural girls and women in India. PloS one 2017;12(12):e0188234.

24. Levitt RB, Barnack-Tavlaris JL. Addressing Menstruation in the Workplace: The Menstrual Leave Debate. In: Bobel C, Winkler IT, Fahs B, et al., eds. The Palgrave Handbook of Critical Menstruation Studies. Singapore: Springer Singapore 2020:561-75.

25. Sommer M, Phillips-Howard PA, Mahon T, et al. Beyond menstrual hygiene: addressing vaginal bleeding throughout the life course in low and middle-income countries. BMJ Global Health 2017;2(2):e000405-e05. doi: 10.1136/bmjgh-2017-000405

26. Hennegan J, Kibira SP, Exum NG, et al. 'I do what a woman should do': a grounded theory study of women's menstrual experiences at work in Mukono District, Uganda. BMJ global health 2020;5(11):e003433.

27. Hennegan J, OlaOlorun FM, Oumarou S, et al. School and work absenteeism due to menstruation in three West African countries: findings from PMA2020 surveys. Sexual and Reproductive Health Matters 2021;29(1):1915940.

28. Zimmerman LA, Sarnak D, Karp C, et al. Impact of experiencing specific side-effects on contraceptive switching and discontinuation in Uganda: Results from a longitudinal PMA Survey. 2020

29. Polis CB, Hussain R, Berry A. There might be blood: a scoping review on women's responses to contraceptive-induced menstrual bleeding changes. Reproductive health 2018;15(1):114.

30. Von Elm E, Altman DG, Egger M, et al. The Strengthening the Reporting of Observational Studies in Epidemiology [STROBE] statement: guidelines for reporting observational studies. Gaceta Sanitaria 2008;22(2):144-50.

31. Carpenter S. Ten steps in scale development and reporting: A guide for researchers. Communication Methods and Measures 2018;12(1):25-44.

32. Bech P, Gudex C, Johansen KS. The WHO (Ten) well-being index: validation in diabetes. Psychotherapy and psychosomatics 1996;65(4):183-90.

33. Topp CW, Østergaard SD, Søndergaard S, et al. The WHO-5 Well-Being Index: a systematic review of the literature. Psychotherapy and psychosomatics 2015;84(3):167-76.

34. Afrobarometer. Surveys and methods: Afrobarometer; 2018 [accessed Accessed, September 2018 http://www.afrobarometer.org/surveys-and-methods.

35. Hennegan J, Nansubuga A, Akullo A, et al. The Menstrual Practices Questionnaire (MPQ): development, elaboration, and implications for future research. Global health action 2020;13(1):1829402.

36. Rosseel Y. lavaan: An R Package for Structural Equation Modeling. Journal of Statistical Software 2012;48(2):1-36.

37. Boateng GO, Neilands TB, Frongillo EA, et al. Best practices for developing and validating scales for health, social, and behavioral research: a primer. Frontiers in public health 2018;6

38. MacCallum RC, Browne MW, Sugawara HM. Power analysis and determination of sample size for covariance structure modeling. Psychological methods 1996;1(2):130. 
39. Gadermann AM, Guhn M, Zumbo BD. Estimating ordinal reliability for Likert-type and ordinal item response data: a conceptual, empirical, and practical guide. Practical Assessment, Research \& Evaluation 2012;17(3)

40. Kenny DA. Measuring Model Fit http://davidakenny.net/cm/fit.htm2020 [accessed June 122021.

41. Rafa M, Moyer JD, WanG X, et al. Estimating District GDP in Uganda: USAID

Frederick S Pardee Center for International Futures, University of Denver, 2017.

42. UNICEF. Going beyond monetary poverty: Uganda's multidimensional poverty profile. Kampala, Uganda: UNICEF Uganda Country Office, 2020.

43. Caruso BA, Cooper HL, Haardörfer R, et al. The association between women's sanitation experiences and mental health: A cross-sectional study in Rural, Odisha India. SSMpopulation health 2018;5:257-66.

44. Caruso BA, Clasen T, Yount KM, et al. Assessing women's negative sanitation experiences and concerns: the development of a novel sanitation insecurity measure. International Journal of Environmental Research and Public Health 2017;14(7):755. 